\title{
Protección y Mejoramiento Biotecnológico en el Ecuador.
}

\author{
Protection and Biotechnological
}

Improvement in Ecuadorn

\section{Diego Orellana Sánchez*}

Investigador jurídico independiente

Infomación del Artículo

Original - Ruptura, 2020

Artículo recibido / Received: 10 de mayo, 2020

Artículo aceptado / Accepted: 12 de junio, 2020

\section{Citación}

Orellana, D. (2020). Protección y mejoramiento biotecnológico en el Ecuador. Revista Ruptura de la Asociación Escuela de Derecho PUCE. Edición 2020, p (577-588).

DOI: $10.26807 /$ rr.vi02.54

Resumen: El presente artículo contrasta el mejoramiento y la protección de la Propiedad Intelectual en cuanto a los cambios en el sector productivo, económico y político en el Ecuador con una rama especifica de la materia antes mencionada denominada como "Obtenciones Vegetales". Para lograr encaminar el objeto de la presente investigación, el artículo se centrará en el análisis de conceptos fundamentales, el reconocimiento de la normativa aplicable y además los órganos competentes, en el caso concreto se analizará la SENADI, la cual entre sus funciones está garantizar la adquisición y ejercicio de los derechos de PI de conformidad con el Código Orgánico de la Economía Social de los Conocimientos, Creatividad e Innovación. Como aporte a su efectividad también es importante

* $\quad$ Estudiante de quinto semestre de la Facultad de Jurisprudencia de la Pontificia Universidad Católica del Ecuador. Correo electrónico: diegoorellana.2468@gmail.com 
recalcar el énfasis del artículo con el Análisis Económico del Derecho con respecto a los derechos reconocidos y con la importancia de su aplicabilidad, esto con el objetivo de lograr establecer un camino para el fortalecimiento de los derechos y así generar un impacto económico positivo en la sociedad ecuatoriana.

Palabras clave: Propiedad intelectual, Obtenciones Vegetales, Transgénicos, SENADI, Análisis Económico del Derecho.

\begin{abstract}
This article contrasts the improvement and protection of Intellectual Property in terms of changes in the productive, economic and political sector in Ecuador with a specific branch of the aforementioned subject called "Plant Varieties". In order to direct the object of this investigation, the article will focus on the analysis of fundamental concepts, the recognition of the applicable regulations and also the competent department, in the specific case the SENADI will be analyzed, which among its functions is to guarantee the acquisition and the exercise of IP rights in accordance with the Organic Code of the Social Economy of Knowledge, Creativity and Innovation. As a contribution to its effectiveness, it is also important to emphasize the importance of the article with the Economic Analysis of Law with respect to the recognized rights and with the importance of its applicability, this with the aim of establishing a path for the strengthening of rights and thus generate a positive economic impact on Ecuadorian society.
\end{abstract}

Keywords: Intellectual property, Plant Varieties, Transgenic, SENADI, Economic Analysis of Law.

\title{
Introducción
}

La Propiedad Intelectual se relaciona con la protección de las creaciones de la mente: invenciones, obras literarias y artísticas, así como símbolos, nombres e imágenes utilizados en el comercio (OMPI ${ }^{1}$,

1 La Organización Mundial de la Propiedad Intelectual es un organismo especializado del Sistema de Naciones Unidas, creado el 14 de julio de 1967 
1967). La adherencia de los Estados a la Organización Mundial de la Propiedad Intelectual garantiza la protección de las obras del intelecto humano. Es por ello que, cuando Ecuador ingresa a la OMPI en 1998 a su vez crea el primer ente gubernamental nacional para la protección de $\mathrm{PI}^{2}$, el Instituto Ecuatoriano de Propiedad Intelectual se encargaba de velar por los derechos sobre las creaciones intelectuales.

Sin embargo, el proceso de protección de la PI en el Ecuador inició en 1895 con el registro de la primera marca en el país. En este año Ecuador se encontraba bajo el gobierno del General Eloy Alfaro, quien fue el impulsor de la Revolución Liberal. Es decir, la protección de la PI guarda conformidad con los cambios en el sector productivo, económico y político que se produjeron en aquel momento, gracias al incremento en las exportaciones del cacao (Boom Cacaotero).

"Se calcula que durante ese período se sembraron cerca de $14 \mathrm{mi}-$ llones de plantas, que seguirían aumentando hasta 70 millones entrado el siglo XX. De este modo, el cacao pasó de representar el 50 por ciento del total de exportaciones hacia la mitad del siglo, hasta un máximo de 75 por ciento en su último cuarto" (Aspiazu, 2018).

La tecnificación de las plantaciones de cacao mejoró la calidad del producto nacional, razón por la cual su demanda rivalizaba internacionalmente "siete u ocho mazorcas producían una libra de grano seco, en contraste con las 11 y hasta 14 requeridas por las variedades desarrolladas en otros países" (Aspiazu, 2018).

\section{Metodología}

El presente ensayo se focalizará en una rama de la PI que es conocida como las Obtenciones Vegetales, para lo cual se realizará un análisis descriptivo de las instituciones y la normativa vigente que

2 Propiedad Intelectual. 
las protegen; con observancia al Análisis Económico del Derecho ${ }^{3}$ y su impacto en la productividad nacional.

\subsection{La obtención vegetal}

La obtención vegetal para Pablo Robledo (2006) "es una producción científica derivada del trabajo intelectual de una persona u organización en el que combinó sus conocimientos científicos y técnicos de la manera que considero más apropiada para lograr los resultados propuestos". La persona que haya creado o descubierto y desarrollado una variedad, el empleador de la persona antes mencionada o que haya encargado su trabajo, o el derechohabiente de la primera o de la segunda personas mencionadas, según el caso, se conoce como Obtentor (Ley de la Propiedad Intelectual, 2006, art. 249).

Se entenderá por descubrimiento, la aplicación del intelecto humano a toda actividad que tenga por finalidad dar a conocer características o propiedades de la nueva variedad o de una variedad esencialmente derivada en tanto ésta cumpla con los requisitos de novedad, distinción, homogeneidad y estabilidad. No se comprende el mero hallazgo. No serán sujetas de protección las especies que no hayan sido plantadas o mejoradas por el hombre (Ley de la Propiedad Intelectual, 2006, art. 249).

De igual manera, es importante mencionar que para tener los derechos de obtentor debe existir una muestra viva suministrada por el solicitante, en la cual se realizarán las pruebas correspondientes para verificar la novedad, distinción, homogeneidad y estabilidad del descubrimiento.

3 Según Adriana García y Dirk Zavala (2017) el Análisis Económico del Derecho (AED) es una forma de estudiar al derecho que difiere de las formas tradicionales. A través de este tipo de análisis se pretende el uso de las herramientas económicas para analizar sistemas normativos, teniendo como principal objetivo la búsqueda de la eficiencia en los sistemas legales. 


\subsection{Instituciones gubernamentales}

La primera Institución Gubernamental encargada de la protección de la PI fue el IEPI ${ }^{4}$, el cual era un órgano público adscrito a la Secretaria Nacional de Educación Superior, Ciencia, Tecnología e Innovación ${ }^{5}$. No obstante, el 3 de abril de 2018, el presidente Lenín Moreno Garcés mediante el Decreto Ejecutivo 356, transforma al IEPI en SE$\mathrm{NADI}^{6} \mathrm{y}$ le otorga nuevas atribuciones.

La SENADI funciona como Subsecretaría General y entre sus funciones está garantizar la adquisición y ejercicio de los derechos de PI de conformidad con el Código Orgánico de la Economía Social de los Conocimientos, Creatividad e Innovación. Realizar estudios e investigaciones relativas a temas de PI que considere pertinentes. Actuar en coordinación con las dependencias competentes en la negociación de tratados y otros instrumentos internacionales en materias relativas a PI y conocimientos tradicionales. Tramitar y resolver las oposiciones que se presenten sobre el registro de derechos de PI. Tramitar todos los procesos de observancia de los derechos de PI, de los conocimientos tradicionales en el ámbito administrativo. Sustanciar los procedimientos de otorgamiento y registro de los derechos sobre nuevas obtenciones vegetales y administrar el depósito de las muestras vivas (Decreto Ejecutivo 356, 2018).

\footnotetext{
4 Instituto Ecuatoriano de Propiedad Intelectual.

5 Conocida como SENESCYT es la autoridad nacional competente en materia de derechos intelectuales (COESCCI, 2016, art. 10).

6 Servicio Nacional de Derechos Intelectuales.
} 


\subsection{Normativa vigente}

La normativa vigente en el Ecuador se puede clasificar de la siguiente manera:

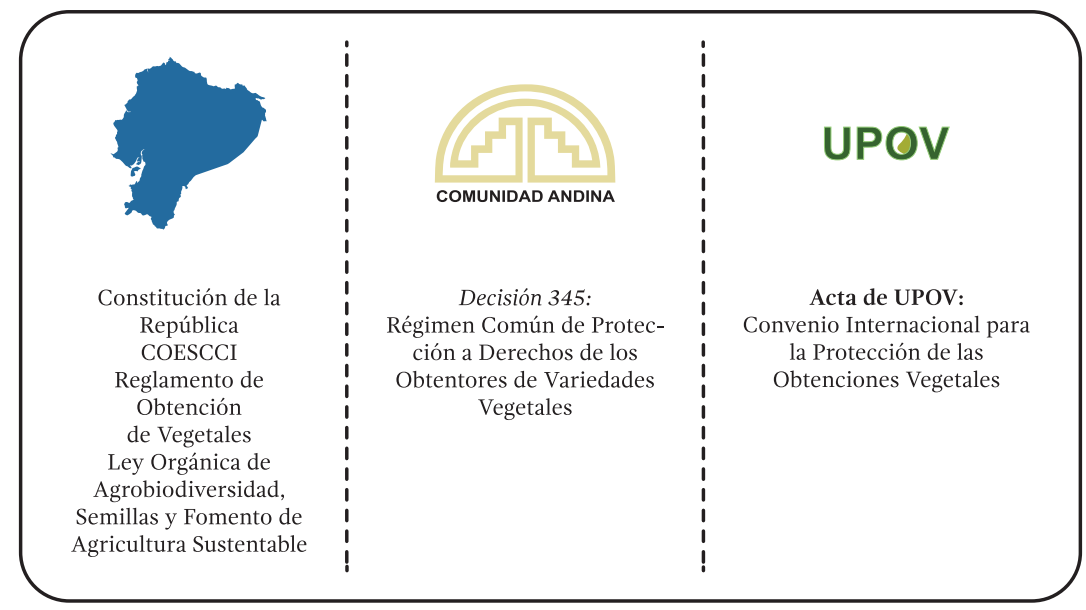

Fuente: SENADI, obtención vegetal, normativa vigente ${ }^{7}$.

Actualmente, la normativa constitucional en la sección de biodiversidad declara al Ecuador libre de cultivos y semillas transgénicas. Excepcionalmente, y solo en caso de interés nacional debidamente fundamentado por la Presidencia de la República y aprobado por la Asamblea Nacional, se podrán introducir semillas y cultivos genéticamente modificados. (...). Se prohíbe la aplicación de biotecnologías riesgosas o experimentales (CRE, 2008, art. 401).

En contra parte, la Ley Orgánica de Agrobiodiversidad, Semillas y Fomento de Agricultura Sustentable en su art. 56 establece que: "se permite el ingreso de semillas y cultivos transgénicos al territorio nacional, únicamente para ser utilizados con fines investigativos. En caso de que se requiera el ingreso para otros fines distintos, se deberá seguir el procedimiento establecido en la Constitución

$7 \quad$ La información es de la fuente citada, sin embargo, la diagramación me pertenece. 
para tal efecto (...). Esta problemática se produce después de una objeción parcial ${ }^{8}$ del expresidente Rafael Correa, la cual vulnera los preceptos constitucionales.

\subsection{Uso de transgénicos}

Los transgénicos son organismos vivos que han sido creados artificialmente manipulando sus genes. Las técnicas de ingeniería genética consisten en aislar segmentos del ADN (el material genético) de un ser vivo (virus, bacteria, vegetal, animal e incluso humano) para introducirlos en el material hereditario de otro (El Universo, 2018).

Frente al uso de transgénicos se mantienen dos posturas. En primer lugar, el rechazo a estos productos, consecuencia de organizaciones ambientales, se fundamenta en los peligros ambientales y a la salud que representan si no existen los mecanismos adecuados para la prevención. Por otro lado, Sandra Sharry refuta el anterior argumento y asegura que "en el caso de los $\mathrm{OGM}^{9}$, no existen riesgos a la salud pública o a la biodiversidad, los riesgos a los que siempre se apelan derivan del sistema económico y de las reglas por las que este se rige".

\section{Resultados}

La obtención vegetal tiene como finalidad ampliar el mercado y disminuir los costos de producción. Esta ampliación debe acompañarse de una legislación que incentive al obtentor con mayores beneficios y una protección eficaz.

Según datos, del SENADI en 2018 en Ecuador se incrementó en un $4,93 \%$ las solicitudes ingresadas por obtenciones vegetales y conocimientos tradicionales en relación con el año anterior. El 90,59\% de

8 En la objeción parcial a la LOASFAS se introduce el texto normativo anteriormente mencionado.

9 Organismo genéticamente modificado 
las solicitudes ingresadas corresponden al tipo de cultivo ornamental y el 70,59\% de las solicitudes resueltas corresponden a concesiones de derechos de obtentor.

SOLICITUDES INGRESADAS
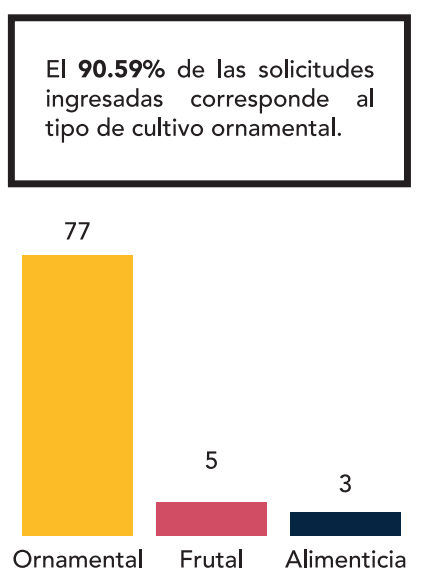

SOLICITUDES RESUELTAS

El $70.59 \%$ de las solicitudes ingresadas corresponde a concesiones de derecho de obtentor.

60

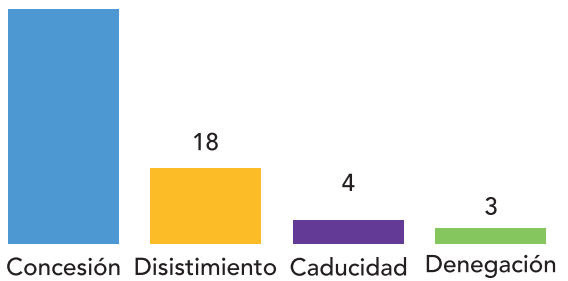

Fuente: SENADI, Gaceta 647, Estadísticas 2018.

Es importante aclarar que la declaración constante en el art. 401 de la norma constitucional se halla vigente.

\section{Discusión}

En este punto se hará un Análisis Económico del Derecho con respecto a los derechos del obtentor, las transnacionales y los transgénicos.

Para efectos del AED en materia de "regulaciones sobre el PI se busca equilibrar el beneficio del obtentor y los de la población general al acceder al conocimiento" (Massot, 2006). Las transnacionales son un potencial obtentor de estos beneficios, aunque cargadas de un negativo sesgo político, de parte de la población nunca serán 
aceptadas como una solución a la productividad de un país. Este tercer personaje complica la armonización de la relación inversa "trade off"

El trade off en la sociedad es determinado por una serie de cambios económicos los cuales dependerán de la eficiencia del Estado para cubrir las necesidades de la población. Cabe recalcar que este proceso es gradual, razón por la cual la legislación debe proteger a ambos extremos de las fallas en el mercado.

Las transnacionales, en ese sentido, juegan un rol importante puesto que su estancia en un Estado dependerá de la seguridad jurídica que le brinde. De igual manera, resulta clave entender que la inversión extranjera genera competitividad en el mercado.

El fortalecimiento de los derechos (sea por la actualización de la legislación o por un efectivo control del mercado ilegal) genera un impacto económico positivo derivado del mayor retorno de las inversiones en investigación y desarrollo constituiría una puerta de acceso para estas empresas e instituciones, a fin de enfrentar desafíos de envergadura, posiblemente relacionados con las áreas más modernas de la biotecnología vegetal. Por otro lado, el debilitamiento de los derechos de propiedad intelectual o el mantenimiento de la actual situación tendría un impacto neutro o negativo sobre la industria nacional y las instituciones oficiales, las cuales, por su necesidad de establecer convenios de vinculación tecnológica para acceder a desarrollos biotecnológicos o para la introducción de variedades terminadas a fin de desarrollarlas localmente, verían disminuidas sus posibilidades por la reticencia de estas empresas a permitir el acceso de sus tecnologías (Rapela, 2006, p.60-61).

10 El trade off se refiere a la relación costo- beneficio. En este caso cada parte obtendrá un beneficio y también asumirá una responsabilidad; resulta importante para el estudio establecer que no existe un equilibrio perfecto. 
La vinculación tecnológica y el desarrollo biotecnológico ${ }^{11}$ nacional resulta escaso aun en comparación regional, puesto que: "la inversión proviene, en su mayoría, de fondos públicos, y la poca participación de la empresa privada en el tema es uno de los factores mas limitantes para su desarrollo" (Portafolio, 2008). Con relación a la tecnificación y la innovación de cada país, se plantean si el trade off entre población, transnacionales y los obtentores locales puede llegar a ser lo suficientemente eficiente y equilibrada.

\section{Conclusiones}

La productividad nacional hasta la actualidad se ha visto limitada por políticas públicas ineficientes que mantienen un mismo modelo de subdesarrollo estatal, la innovación y descubrimientos en el Ecuador son muy bajos comparados al nivel de biodiversidad pertenecientes. Las limitaciones constitucionales impiden un enfoque óptimo dirigido a incentivar la investigación y el mejoramiento vegetal.

La matriz productiva actual se basa en la dependencia a las materias primas que nos brinda nuestro territorio. Los ingresos estatales, en materia vegetal, se obtienen de la exportación de dos productos principales: cacao y café, esto perjudica a la industrialización porque limita el panorama y no plantea alternativas económicas de sustento.

Promover el desarrollo, innovación y mejoramiento agrícola con incentivos para los creadores intelectuales en el país requiere de una restructuración institucional y una reformulación legal que procure conseguir el equilibrio entre los titulares de los derechos de obtentor y el bienestar social, exigiendo siempre un efecto positivo y dinámico.

La reactivación económica del Ecuador no puede depender solo del Estado, resulta necesario incentivar la inversión extranjera. El tratamiento a las transnacionales, su tecnología y su tecnificación debe

11 La vinculación tecnológica y desarrollo biotecnológico comprende el uso de transgénicos y semillas genéticamente modificadas. 
ser aceptado y a su vez sometida a un mecanismo eficiente de control que implemente medidas de seguridad hacia la población.

Finalmente, con acciones afirmativas proporcionadas se puede proteger la industria local, delimitando un mercado más justo, seguro y competitivo nacional e internacionalmente. Para establecer otro modelo económico en el cual las materias primas nos permitan generar mayor productividad a través de nuestro propio mejoramiento industrial.

\section{Referencias bibliográficas}

Aspiazu, R. (2018). El ‘boom' del cacao ecuatoriano (1870-1925). Quito, Ecuador: El comercio. Recuperado de https://www.elcomercio.com/ boom-cacao-ecuatoriano-colonia-economia.html

El Universo. (2018). Transgénicos son ilegales en sembríos, pero sí se consumen en Ecuador. Guayaquil, Ecuador: El Universo. Recuperado de https://www.eluniverso.com/noticias/2018/09/16/nota/6954224/transgenicos-son-ilegales-sembrios-si-se-consumen-ecuador

García, A. y Zavala, D. (2017). ¿Qué es el análisis económico del derecho? Derecho en Acción. Recuperado de http://derechoenaccion.cide.edu/ que-es-el-analisis-economico-del-derecho/

IEPI. (2015). La Propiedad Intelectual en el Ecuador. Video. Recuperado de https://wwww.youtube.com/watch?v=Vx9CwIsMXUA

Massot, J. (2006). Análisis Económico de los derechos de propiedad intelectual en semillas. En: Innovación y propiedad intelectual en mejoramiento vegetal y biotecnología agrícola. Buenos Aires, Argentina: Heliasta

Navarro, J. (2019). Propiedad Intelectual - Ecuador. Video. Recuperado de https://www.youtube.com/watch?v=5Z1dIrMTxrc

OMPI. (1967). Organización Mundial de la Propiedad Intelectual. 
Portafolio. (2008). Avanza la biotecnología en América Latina, 10 países de la región la utilizan entre 23 del mundo, según IICA. Portafolio. Recuperado de https://www.portafolio.co/economia/finanzas/avanza-biotecnologia-america-latina-10-paises-region-utilizan-23-mundo-iica-274712

Rapela, M. (2006). Características de la propiedad varietal general y de la oferta de semillas de trigo y soja en Argentina. En: Innovación y propiedad intelectual en mejoramiento vegetal y biotecnología agrícola. Buenos Aires, Argentina: Heliasta.

Robledo, P. (2006). Los derechos del obtentor de variedades vegetales en Colombia. Bogotá, Colombia: Universidad Externado de Colombia.

SENADI. (2013). Obtenciones Vegetales. Quito, Ecuador. Recuperado de https://www.derechosintelectuales.gob.ec/obtenciones-vegetales/

SENADI. (2019). Gaceta 647: Estadísticas 2018. Recuperado de http://gaceta.propiedadintelectual.gob.ec:8180/Gacetas/647/\#p=1

\section{Legislación}

Asamblea Nacional del Ecuador. Código Orgánico de la Economía Social de los Conocimientos, Creatividad e Innovación. [Código 1 de 2016]. (1 de diciembre de 2016). RO. 899 de 9 de diciembre de 2016.

Asamblea Nacional del Ecuador. Ley Orgánica de Agrobiodiversidad, Semillas y Fomento a la Agricultura Sustentable. [Ley 0 de 2017]. (8 de junio de 2017). RO. 10 de 8 de junio de 2017.

Congreso Nacional del Ecuador. Ley de Propiedad Intelectual. [Ley 1 de 2006]. (28 de diciembre de 2006). RO. 426 de 28 de diciembre de 2006.

Constitución de la República del Ecuador. [Const.]. (2008). 2da. Ed. CEP.

Presidencia de la República del Ecuador. Decreto Ejecutivo 356. (3 de abril de 2018). RO. de 3 de abril de 2018. 